\title{
Pengembangan Lembaran Kerja Peserta Didik Berbasis Inkuiri Terbimbing pada Mata Pelajaran PPKn untuk siswa SMPN 32 Padang
}

\author{
Fahmi Kafillah, Azwar Ananda \\ Program Studi Pendidikan Pancasila dan Kewarganegaraan \\ Universitas Negeri Padang \\ E-mail: fahmikafillah0@gmail.com
}

\section{ABSTRAK}

Penelitian ini bertujuan untuk menghasilkan Lemberan Kerja Perserta Didik (LKPD) berbasis Inkuri Terbimbing Pada Mata Pelajaran PPKn untuk Siswa SMP Negeri 32 Padang. LKPD ini di lengkapi dengan komponen model pembelajaran berbasis Inkuiri Terbimbng serta di tambah dengan kata-kata motivasi sehingga meningkatkan minat belajar siswa. Dalam Penelitian ini peneliti juga melakukan uji validitas dan uji praktikalitas agar menemukan kevalitan dalam aspek kelayakan isi, keabsahan, penyajian dan kegrafikan pada penggunaan LKPD. LKPD ini di lakukan uji Praktisan dalam segi aspek kemudahan pengguna, efesiensi dan manfaat dalam pembelajaran. Jenis penelitian ini adalah Developmen and Reserch (RED) yakni penelitian kuantitatif dengan menggunakan uji angket yang di sebarkan kepada tim validitas dan siswa dalam menentukan praktikalitas. Penelitian dilaksanakan di Lubuk Minturun, kawasan Sungai Lareh Kota Padang bertempat di SMP 32 Negeri Padang. Informan penelitian ini yakni guru PPKN SMP Negeri 32 Padang, serta siswa-siswi kelas VII SMP Negri 32 Padang. Teknik pengumpulan data yakni menggunakan angket validitas dan praktikalitas, serta menggunakan model ADDIE (Analisis, Designt, Developmen, Implementation and Evolusion) akan tetapi dari kelima tahapan ini peneliti hanya menngunakan 3 tahapan saja yakni (Analisis, Design and Devolopmen). Hasil Penelitian menunjukan bahwa telah di hasilkan Lembaran Kerja Perserta didik Berbasis inkuiri Terbimbing pada Mata Pelajaran PPKN Untuk siswa SMP N 32 Padang yang valid dengan nilai $92,50 \%$ dan praktis $81,21 \%$. Maka dapat di simpulkan validitas dan praktikalitas LKPD dapat di gunkan oleh guru dan siswa.

Kata Kunci: Lembaran Kerja Perserta Didik, Inkuiri, Siswa.

\section{ABSTRACT}

This study is aimed at producing studen worksheet (LKPD) based on Guided Inquiry in civic education Subjects for Students of Padang State Middle School 32. LKPD is equipped with Guided Inquiry-based learning tools and added motivational words to increase students' interest in learning. In this study the researchers also tested the validity in the components of the feasibility of content, validity, and presentation on the use of LKPD. This LKPD is tested for its practicality in terms of user convenience components, efficiency and benefits in learning. This type of research is Reserch and Developmen $(R \mathcal{E} D)$, namely quantitative 
research using questionnaires distributed to validators and students. This study used the ADDIE model (Analysis, Design, Development, Implementation, and Evaluation) in the use of the ADDIE model. The researcher only reached three stages, namely (Analysis, Design, Development). The research was conducted at Padang State Middle School 32. The informants of this study were civic education teachers from Padang State Middle School 32, and also seventh grade students of Padang State Middle School 32. The technique of collecting data used validity and practical questionnaires. The results of the study showed the validity of studen worksheet (LKPD) based on Guided Inquiry in civic education Subjects for Students of Padang State Middle School 32 was $92.50 \%$ for the score and for practically was $81.21 \%$. Then it can be concluded that the LKPD can be used by teachers and students

Keywords : Student Worksheet (LKPD), Inquiry, Students

CC (D) (2) This work is licensed under the Creative Commons Attribution-ShareAlike 4.0 International License. @2019 by author and Universitas Negeri Padang.

\section{PENDAHULUAN}

Didalam UU No 14 tahun 2005 tentang guru dan dosen pada bab IV pasal 10 menyatakan ada 4 kompetensi yang harus dimiliki guru yakni kompetensi pedagogik, kompetensi kepribadian, kompetensi sosial, dan kompetensi profesional. Oleh karena itu, peranan guru dalam dunia pendidikan sangat berperan aktif untuk mewujudkan sistem pendidikan yang lebih baik. Guru juga dituntut untuk dapat berfikir kreatif dan inovatif agar dapat mengembangkan pembelajaran dengan baik serta memahami teknologi dalam menyampaikan metode pembelajaran sehingga pembelajaran menjadi tidak kaku dan tidak membosankan (Irwan, Luthfi, \& Waldi, 2019).

Agar pembelajaran menjadi menyenangkan maka guru harus mampu melakukan model pembelajaran yang kreatif sehingga terciptanya suasana pembelajaran yang diharapkan guru. Supaya terwujudnya tujuan pendidikan Nasional guru harus menguasai dari segala aspek pembelajaran salah satunya adalah penguasaan IPEK (Ilmu Penngetahuan dan Teknologi). Dalam Penguasaan IPTEK guru harus mampu menciptakan bahan ajar yang kereatif dan inovatif dalam menunjang proses pembelajaran. Menurut (Rusman, 2012) belajar Merupakan suatu cara untuk menambah pengetahuan sehingga dapat memberikan manfaat dan pengalaman. Semntara Pembelajaran merupakan suatu organisasi yang terdiri atas beberpa komponen sehingga berpengaruh terhadap orang lain (Hamalik, 2012).

Pembelajaran

Pendidikan Pancasila dan Kewarganegaraan atau (Civic Education/Citizenship Education) meupakan merupakan suatu hubungan timbal balik dengan rakyat serta kedua belah pihak di ikat dengan sebuah kesepakatan hukum dan Undang-Undang (Ananda, 2012). Dalam menunjang proses pembelajaran Pendidikan Pancasila dan kewarganegaraan guru harus mampu memahami Permendiknas No.22/2016 tentang penetapan standar isi dalam kurikulum pendidikan dasar dan menengah 
mengonsepkan pentingnya PPKn, yaitu:

Mata pelajaran pendidikan

kewarganegaraan merupakan matapelajaran

yang memfokuskan pada pembentukan

warganegara yang memahami dan mampu melaksanakan hak-hak dan kewajiban untuk menjadi warga Indonesia yang cerdas, terampil yang di amanatkan oleh Pancasila dan UUD 1945.

Dari hasil penelitian di SMP Negeri 32 Padang maka penulis menemukan permasalahan yakni bahan ajar yang di gunakan oleh siswa masih banyak komponen yang kurang lengkap dan model pembelajaran yang membosankan. Dalam pengunaan LKPD di sekolah belum meningkatkan minat belajar siswa pada saat pembelajaran. Oleh karena itu, siswa sering mengalami kesulitan dalam memahami pelajaran PPKN berlangsung. Permasalahan tersebut dapat di atasi dengan menyediakan lembaran Kerja Perserta Didik (LKPD) yang sesuai dengan kebutuhan siswa. LKPD (Lembaran Kerja Peserta Didik) merupakan Lembaran yang harus di kerjakan oleh perserta didik berisi petunjuk dan langkah pembelajaran (Devi, 2009). Dalam menunjang proses pembelajaran maka di gunakanlah pendekatan pembelajaran. Pendekatan pembelajaran merupakan suatu strategi dalam merancang pembelajaran sehingga pembelajaran berjalan dengan efektif dan efisien. Salah satu pendekatan pembelajaran untuk kurikulum 2013 adalah pendekatan inkuiri.

Inkuiri terbimbing merupakan sebuah pendekatan pembelajaran yang mana siswa mampu menemukan konsep - konsep pembelajaran secara mandiri dalam menemukan pengetahuan, Ide, dan Informasi melalui usaha sendiri (Lufri, 2007). Oleh karena itu, Siswa menjadi aktif dan kreatif saat pembelajaran terutama pada pembelajaran Pendidikan Pancasila dan Kewarganegaraan. Dalam penelitian ini penulis merancang LKPD dengan menggunakan Kompetensi Dasar (KD) 3.3. membahas perumusan dan pengesahan Negara Republik Indonesia. LKPD yang menggunakan model pembelajaran Inkuri Terbimbing dan memiliki karakteristik model pembelajaran inkuiri serta adanya kata-kata motivasi yang diselipkan di lembaran LKPD maka di harapkan siswa lebih aktif dalam pembelajaran PPKN berlangsung. Dari permasalahan tersebut penulis telah melakukan penelitian mengenai "Lembaran Kerja Perserta Didik Berbasis Inkuiri Terbimbing pada Matapelajaran PPKN untuk Siswa SMP N 32 Padang".

Tujuan Penelitian ini menghasilkan Lembaran Kerja Perserta Didik berbasis Inkuiri terbimbing Pada Mata pelajaran PPKN. Lembaran Kerja Perserta Didik (LKPD) yang di lengkapi dengan Perangkat pembelajaran Inkuiri terbimbing dan kata kata motivasi dari para tokoh Minang Kabau. LKPD ini tentunya dapat memberikan manfaat untuk siswa yakni dapat mempermudah proses pembelajaran PPKN serta diharapkan mampu mengaspekan dan mengamalkan nilainilai pancasila yang ada. LKPD ini juga di lakukan uji validitas dan praktikalitas agar LKPD ini menjadi Valid dan layak digunakan oleh siswa dan guru.

\section{METODE PENELITIAN}

Jenis Penelitian ini adalah Penelitian Pengembangan (research and development) (Ananda, 2014). Sedangkan Produk yang di hasilkan 
adalah Lembaran Kerja Perserta Didik Berbasis Inkuiri Terbimbing Pada Mata Pelajaran PPKN Untuk siswa SMP N 32 Padang. Materi yang akan di bahas dalam LKPD ini adala KD 3.3 Perumusan dan Pengesahan Negara Republik Indonesia. Pengumpulan data di gunakan data primer dan data sekunder (Siregar, 2013). Penelitian ini di laksanakan SMP Negeri 32 Padang.

Dalam melaksanakan metode penggembangan peneliti menggunakan model ADDIE yaitu Analisis, Design, Development, Implementation, and Evaluasion (Pribadi, 2009). Pada Penelitian ini model ADDIE dilakukan peneliti hanya sampai pada tahapan ketiga yaitu Design karna keterbatasan waktu dan biaya penelitian. Penelitian ini juga sesuaikan dengan tujuan penelitian yaitu menciptakan Lembaran Kerja Perserta Didik (LKPD) untuk siswa SMP kelas VII dan menemukan nilai validitas dan Praktikalitas dengan melakukan uji angket. Oleh karena itu, perancangan LKPD peneliti hanya mencari nilai validitas dan praktikalis. Teknik pengumpulan data pada penelitian in menggunakan angket (kuisioner). Dalam pengskoran jawaban reponden dalam angket di lakukan berdasarkan skala likert.

\section{HASIL DAN PEMBAHASAN}

Berdasarkan Penelitian yang di laksanakan maka di peroleh hasil sebagai berikut. Lembaran kerja Perserta didik yang di hasilkan adalah LKPD untuk siswa SMP kelas VII dengan topik Kesejarahan Perumusan dan pengesahan UUD Negara Republik Indonesia Tahun 1945. LKPD yang di hasilkan dalam bentuk tugas dan pembahasan yang akan di kerjakan siswa. Adapun pembagian LKPD ini terdiri dari

1. Abstrak lembaran kerja perserta didik berbasis inkuiri terbimbing berguna untuk melihat gambaran umum dari LKPD ini seperti apa tentunya untuk memberikan informasi seputa LKPD bagi pengguna.

2. Sintak pembelajaran LKPD yang berisikan tahapan dalam mengerjakan LKPD bagaimana langkah-langjah guru untuk memualai pembelajaran Inkuiri terbimbing yang terdapat didalam LKPD agar membantu siswa dan guru dalam menggunakan LKPD ini. Sintak pembelajaran LKPD terdiri dari: orientasi, rumusan masalah, hipotesis, mengumpulkan data, menguji hipotesis dan merumuskan kesimpulan.

3. Pencapaian kompetensi Pada tahapan pencapain kompetensi yang didesign oleh peneliti menggunakan KD sesuai dengan kurikulum 2013. Desain yang di buat dalam tahapan kompetensi ini menggunakan Microsoft power point 2007. Jenis huruf Times new roman ukuran tulisan $12 \mathrm{pt}$, serta spasi 1,0. Untuk lebih jelasnya dapat di lihat pada gambar di bawah ini.

4. Pada tahapan inkuiri terbimbing ini yakni penjabaran dari tahapan sintak pembelajaran. Tahapan ini lebih spesifik dalam menjabarkan langkah langkah atau tahapan dalam pembelajaran secara lebih komplek. Mulai tahaan orientasi sampai mengumpulkan kesimpulan. tahapan ini di sertai dengan petunjuk pembelajaran agar siswa dan guru lebih 
memahami bagaimna cara penggunaan LKPD.

5. Tahapan mengumpulkan informasi, yakni adanya inti sari pada materi pembelajaran yang di bahas Dalam Lembaran Kerja Peserta didik terdapat Uraian singkat materi mengenai pembahasan dengan KD 3.3 yang membahas mengenai perumusan dan pengesahaan UUD Negara Republik Indonesia Tahnun 1945. Pada tahapan teori tampilan huruf Times New Roman ukuran 20 dan di beri catatan penuh dan sedikit sentuhan gambar anak anak gunanya untuk menarik perhatian peserta didik membaca.

6. Tahapan Aktifitas pembelajaran yang berisikan serangkaian pertanyaan untuk siswa yang di kerjakan secara berkelompok.

7. Soal latihan didalam LKPD ini terdiri dari soal objektif sebanyak 20 soal dan soal esay sebanyak 10 soal agar menambah pemahaman siswa dalam penggunaan LKPD. Dalam pengerjaan soal latihan ini tidak dikerjakan secara perkelompok akan tetapi secara individu. Tingkatan soal yang digunakan sesuai dengan KKO dari C1 sampai kepada C3 yang sesuai dengan tingkat kemampun siswa SMP.

8. LKPD ini dilengkapi dengan "guru menyampaikan" supaya memudahkan guru dalam proses pembelajaran. Penggunaan LKPD berbasis inkuiri terbimbing dengan di bantunya tahapan "guru menyampaikan" memudahkan guru dan siswa dalam menarik sebuah kesimpulan dalam pembelajaran.
9. Pemberian langkah lanjutan yang terdapat didalam LKPD unutk mendambah pemahaman siswa mengenai materi yang dibahas didalam LKPD. Agar memudahkan siswa dalam menjawab langkah lanjutan maka di berikanlah sumber belajar seperti pemberian informasi melalui link youtub dan jurnal yang telah tersedia di dalam LKPD.

10. Pemberian informasi unik seputar sejarah kemerdekaan Indonesia mulai dari upacara bendera pertama kali sampai kepada suara rekaman ulang Presiden Soekarno hal ini untuk menambah wawasanperserta didik. Validitas LKPD ini di uji terhadap beberapa aspek yaitu kelayakan isi, Keabsahan, dan penyajian. Berdasarkan aspek tersebut di kembangkan angket untuk mengetahui validitasnya yang di isi oleh 2 orang validator.

Tabel 1. Daftar Nama Validator LKPD

\begin{tabular}{|c|l|c|}
\hline No & \multicolumn{1}{|c|}{ Nama } & Keterangan \\
\hline 1 & Prof. Dr. Azwar Ananda, MA & Dosen \\
\hline 2 & Mardiyah Hayati S. Pd & Guru \\
\hline
\end{tabular}

Hasil Validitas berdasarkan aspek kelayakan isi di peroleh nilai validitas 96,42\%, aspek keabsahan 91,67\%, dan aspek 94,44\%. Hasil pengujian menunjukan validitas LKPD ini adalah 92,50\% (Valid) hal ini berarti LKPD ini dapat di gunakan guru di sekolah.

Sedangkan hasil uji praktikalitas yang menyangkut kemudahan pengguna, efisiensi dan manfaat di ketahui melalui angket yang berjumlah 13 pertanyaan ditambah kolom komentar di bawahnya yang di 
isi oleh 30 orang siswa maka di hasilkan nilai praktikalitanya melalui aspek penggunaan $81,21 \%$, efisiensi $82,08 \%$ dan Aspek manfaat 80,41\%. Dari ketiga Aspek tersebut di peroleh lah rata-rata nilai praktikalitas $(81,21 \%$,) Sementara itu Praktikalitas juga di uji oleh seorang guru PPKN kelas VII maka di hasilkan dari aspek penggunaan $80.0 \%$, Aspek efisiensi $87,4 \%$ dan aspek manfaat $83,3 \%$ sehingga memperoleh Nilai rata-rata $(83,57 \%)$.

Gambar 1. Diagram Hasil Angket Validitas dan Praktikalitas.

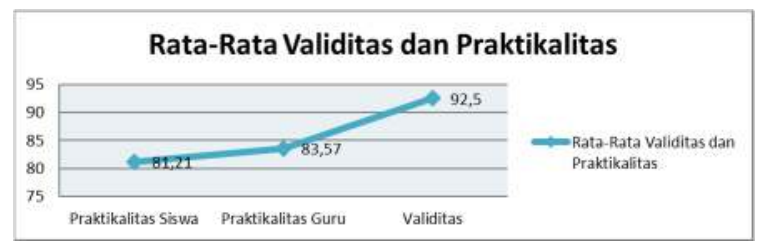

Dari hasil angket di atas maka dapat di katakana bahwa LKPD ini memenuhi syarat untuk menjadi bahan pembelajaran bagi siswa karena menghasilkan LKPD yang valid dan praktis untuk di gunakan oleh gurudan siswa.

Menurut (Prastowo, 2011) bahan ajar LKPD sangat membantu siswa dalam memahami pembelajaran karena lebih sederhana serta lebih komplek dari pada buku.

Macam-macam bentuk LKPD yang umumnya di gunakan oleh perserta didik adalah:

1. LKPD membantu perserta didik dalam menemukan konsepnya sendiri

2. LKPD membantu perserta Didik dalam menerapkan dan mengitegrasikan beberapa konsep yang telah di temukan.

3. LKPD berfungsi sebagai penuntun belajar
4. LKPD Sebagai Penguat pemahaman perserta didik

5. LKPD yang berfungsi sebagai petunjuk pratikum (Prastowo, 2011).

Lembaran Kerja Perserta Didik (LKPD) yang baik dalam merancangnya harus memenuhi beberapa komponen yaitu: Menentukan tujuan pembelajaran yang akan di design dalam LKPD, Adanya pengumpulan menentukan materi dan tugas yang akan kita masukan di dalam LKPD, adanya penyususnan elemen-elemen atau unsur dalam tahapan ini peneliti telah mengabungkan beberapa unsure dari langkah sebelumnya, adanya pemeriksaan dan penyempurnaan.

Sebagaimana temuan Dwi Arimbi menyusun LKS dalam pembelajaran Biologi dan mencobakanya terhadap siswa SMAN 1 Batang Anai dihasilkanya validitas yang di peroleh $81,76 \%$ sementara praktikalitasnya 85,06\% (Praktis). Jadi LKS dalam membantu pratikum biologi mampu menjadikan siswa aktif. Sementara itu, berdasarkan jurnal Ria Istikharah mengenai Pengembangan Lembaran Kerja Perserta Didik (LKPD) Kelas X SMA/MA pada materi Protista berbasis Pendekatan Ilmiah di hasilkan nilai validitas $82 \%$ (Valid) dan praktikalitas 86\% (Praktis). Oleh karena itu, LKPD di buat dapat meningkatkan semangat belajar siswa dalam materi Protista dan LKPD ini di nyatakan sangat layak dalam penggunaan pembelajaran biologi.

Dalam temuan (Dwi, 2015) dan (Ria, 2017) hasil penelitiannya dihasilkan LKS/LKPD yang mempu menunjang minat belajar siswa dalam pembelajaran biologi dan pritikum 
biologi. Sementara peneliti juga menghasilkan Lembaran Kerja Perserta Didik (LKPD) Berbasis Inkuiuri Terbimbing Pada Mata Pelajaran PPKn yang meningkatkan minat belajar siswa serta siswa menjadi aktif dan kreatif saat pembelajaran PPKn berlangsusng. Oleh karena itu, Penggunaan Lermbarab Kerja Perserta Didik mampu meningkatkan hasil belajar siswa dan mampu mmbuat siswa akif dan kreatif. LKPD juga membantu kesulitan proses belajar dan mengar jadi penggunaan LKPD sangat menunjang minat belajar siswa dan mampu memudahkam guru saat proses pembelajaran berlangsung.

\section{KESIMPULAN}

Berdasarkan rumusan masalah, tujuan hasil dan pembahasan penelitian ini telah di hasilkan Lembaran Kerja Perserta Didik (LKPD) Berbasis Inkuiri terbimbing pada mata Pelajaran Pendidikan Pancasila dan Kewarganegaraan (PPKn) untuk siswa SMPN 32 Padang kelas VII. Lembaran Kerja Perserta Didik dalam mata pelajaran PPKN untuk siswa kelas VII yang di kembangkan oleh peneliti di hasilkan nilai validitas $92,50 \%$ dengan kriteria valid dengan demikian LKPD ini dapat di ujikan kepada guru dasn siswa. LKPD yang di lakukan uji Praktikalitas dengan guru PPKn dan 30 orang siswa dengan nilai $81,21 \%$ (Praktis). Maka dalam hal ini LKPD berbasis Inkuri Terbimbing pada mata Pelajaran PPKn bisa di gunakan oleh guru dan siswa serta mampu meningkatkan minat belajar siswa dalam pembelajaran PPKn.

\section{DAFTAR PUSTAKA}

Ananda, A. (2012). Pendidikan Kewarganegaraan (Pkn)
Pendidikan Karakter. Padang: UNP

Ananda, A. (2014). Metode Penelitian Kuantitatif. Padang: UNP.

Arimbi, D. (2015). Pengembangan Lembaran Kerja Siswa Berbasis Inkuiri Terbimbing Pada Materi Protista Untuk Siswa SMAN 1 Batang Anai. Skripsi. Fakultas Ilmu Pengetahuan Alam Universitas Negeri Padang.

Devi. (2009). Pengembangan Perangkat Pembelajaran. Jakarta: PPPPTK IPA.

Hamalik, O. (2012). Proses Belajar Mengajar. Jakarta: Bumi Aksara

Irwan, I., Luthfi, Z. F., \& Waldi, A. (2019). Efektifitas Penggunaan Kahoot! untuk Meningkatkan Hasil Belajar Siswa [Effectiveness of Using Kahoot! to Improve Student Learning Outcomes]. PEDAGOGIA: Jurnal Pendidikan, 8(1), 95-104.

Lufri. (2007). Strategi Pembelajran Biologi. Padang: UNP Press

Prastowo, A. (2011). Panduan Kreatif Membuat Bahan Ajar. Jakarta: Diah Rakyat.

Pribadi, B. (2011). Model desain system pembelajaran. Jakarta: Erlangga

Ria, I. (2017). Pengembangan Lembaran Kerja Perserta Didik (LKPD) Kelas X SMA/MA Pada Materi Pokok ProtistaBerbasis Pendekatan Ilmiah. Jurnal Pendidikan Matematika Dan Sains.

Rusman, (2012). Belajar dan Pembelajaran berbasis Komputer. Bandung: Sinar Baru Algesindo. Siregar, S. (2012). Metode Penelitian Kuantitatif. Jakarta: Kecana. 